\title{
Evaluation of Receptive and Expressive Vocabulary in 6-18 Month's-old Children With Cleft Lip and Palate
}

\author{
${\text { Leila Sedaghati }{ }^{1}, \text { Akbar Darouie }^{1 *}, \text { Fatemeh Derakhshande }^{2}, \text { Mehrdad Memarzade }}^{3}$, Behzad Mahaki $^{4}$
}

1. Department of Speech Therapy, University of Social Welfare and Rehabilitation Sciences, Tehran, Iran.

2. Department of Speech Therapy, School of Rehabilitation Sciences, Isfahan University of Medical Science, Isfahan, Iran.

3. Department of Medicine, School of Medicine, Isfahan University of Medical Science, Isfahan, Iran.

4. Department of Biostatistics and Epidemiology, School of Health, Isfahan University of Medical Sciences, Isfahan, Iran.

Cftation: Sedaghati L, Darouie A, Derakhshande F, Memarzade M, Mahaki B. Evaluation of Receptive and Expressive Vocabulary in 6-18 Month's-old Children With Cleft Lip and Palate. Iranian Rehabilitation Journal. 2016; 14(3):151-156 https://doi.org/10.18869/nrip.irj.14.3.151

: https://doi.org/10.18869/nrip.irj.14.3.151

\section{Article info:}

Received: 11 Feb. 2016

Accepted: 19 Jun. 2016

\section{Keywords:}

Cleft lip and palate, Receptive vocabulary, Expressive vocabulary

\section{A B S T RACT}

Objectives: One of the factors predicting language impairments is an early limited lexicon in children. An early limited lexicon can also lead to limited performances in other language areas. This study was aimed to examine receptive and expressive vocabulary in 8-16 monthold children with cleft lip and palate as a predictor of development in other language areas.

Materials: The MacArthur-Bates Communicative Development Inventory (CDI) was used to collect data. Thirty children with cleft palate/lip and palate who had visited the Isfahan's cleft lip and palate team were analyzed and compared to 30 children without cleft lip and palate.

Results: According to the study results, there was no significant difference between the children with cleft lip and palate and the normal children in terms of the number of words, but the children with cleft lip and palate had significantly less expressive vocabulary than the normal children.

Discussion: The results indicated that children with cleft lip and palate experience a delay in the development of the number of expressive vocabulary, and this delay affects higher levels of language, reading and writing skills of these children. This indicates the importance of providing early evaluations and interventions for children with cleft lip and palate.

\section{Introduction}

tudies have reported that infants and toddlers with Cleft Lip and Palate (CLP) have an increased risk of impairment in speech and language development compared to their peers without CLP. Such toddlers with
CLP have also been reported to suffer from delayed development of global language and delayed vocabulary comprehension and acquirement of first words [1]. In addition, studies on early development of language in children with CLP indicate that they show a delay in the onset of first words and development of early expressive lexicon $[2,3]$. Type and severity of cleft, time of palate

* Corresponding Author: 
repair, efficacy of palate repair, hearing status over time, frequent hospitalizations, parent's attitudes and conflicts, and even other environmental factors affecting the communication are considered as risks to the development of language $[4,5]$. Therefore, children born with cleft palate should be considered as children at risk of language delays and thus, should receive language evaluations from the age of 8 months, for at least every year [6].

In a longitudinal study, Chapman and Hardin-Jones (2014) compared two groups of children with CLP to a matched group without CLP at the ages of 13, 17, 21, and 27 months in terms of the size of expressive lexicon and lexical selectivity. They used the second form of MacArthur Communicative Development Inventory (CDI) to examine the number of expressive vocabulary. Their results indicated that the size of expressive lexicon in the children with CLP was less than that of the normal group at all ages; nevertheless, the difference was significantly higher at 21 and 27 months of age [7].

Using the CDI, Lu and Fletcher (2010) examined 40 infants with CLP at 8-15 months of age in terms of the development of receptive and expressive vocabulary. Their results showed that all the infants with unrepaired CLP had a lower performance in vocabulary comprehension than the normal infants, but this difference was not statistically significant from 8-15 months of age. There was also no significant difference between the two groups from 8-13 months of age in terms of the number of expressive words, but the number of expressive words at 14 and 15 months of age was significantly lower in the children with CLP than the normal children [8].

Yong (2010) compared 43 Chinese Singaporean preschool children with CLP aged between 3-6 years to their normal matches in terms of expressive use of vocabulary and language structure. He used the Singapore English Action Picture Test (SEAPT) to evaluate expressive vocabulary and structure use. The results of the Yong's study indicated that the Chinese Singaporean pre-school children with CLP had many problems in expressive use of structure and expressive vocabulary. He also reported that around $33 \%$ of these children were recognized as children who were likely to have impairments in expressive language. In addition, the boys had significantly more language impairments than the girls [1].

Scherer \& Williams (2008) compared 13 children with CLP with 13 children without CLP. They used the Sequenced Inventory of Communicative Development (SICD) and the CDI in their study. According to their findings, the group of children with CLP showed significantly lower scores on receptive and expressive language [9]. Priester and Goorhuis (2008) compared 43 children aged between 2-2.5 years with CLP with 32 children without CLP in terms of language comprehension and production. Their results showed that the two groups did not have any differences in language comprehension and production [10].

Many studies such as Morrise and Ozannei (2003) have also indicated that children with CLP exhibit receptive impairments in higher ages, but the goal of therapists is to find out when receptive impairments are exhibited for the first time, in order to create preventive interventions for the children in need of therapy [11]. In a longitudinal study, Broen (1998) compared a group of children with CLP with a matched normal group in terms of early cognitive and language development. According to the results, the children with CLP were slower in vocabulary acquisition (approximately, 3 months behind their normal matches) [12]. A study by Scherer and Antonio (1997) on the development of language in children with CLP indicated the relatively high incidence of language impairments, including a delay in onset and development of vocabulary, sentence development, and morphology development; the reason behind the increasing incidence of language deficiencies is unclear [3].

Given that there are no studies in Iran on the development of language in infants and children with CLP at this age and on the differences between these children and normal children, $\mathrm{n}$, this study can help us to find a better understanding of the language deficiencies in these children and provide early interventions. Our findings will also be helpful since a delay in diagnosis and evaluation can have irreparable impacts on these children.

\section{Methods}

This was a cross-sectional and descriptive-analytical study on 30 children with CLP who were referred to the Imam Hossein Children Hospital and 30 children without CLP. The children were selected using a convenience sampling method; those who fulfilled the inclusion criteria were included in the study. The normal children were selected using a purposive sampling method from 5 different parts of Isfahan so that they meet the inclusion criteria and match the study group in terms of age, sex, socioeconomic status, and mother's education level.

Both groups were homogeneous on these factors. The inclusion criteria were being aged between 8-16 months, mother's full-term pregnancy (over 36 weeks), not having serious hearing problems, not having cognitive problems, not having serious medical or neurologi- 
cal problems affecting speech and language, and being monolingual (speaking Persian language). The inclusion criteria were analyzed using medical files, interviews, histories obtained from mothers, observing children, and informal evaluations by a researcher. Immittance Audiometry (IA) and Visual Reinforcement Audiometry (VRA) were used by an audiologist to ensure the hearing status of the children with CLP.

The MacArthur-Bates CDI was used to examine the number of expressive and receptive vocabulary. The first form of the CDI was translated into Persian by Kazemi et al. (2006); they found a Cronbach's alpha of .95 and an adjusted correlation coefficient of above .85 for the scale [13]. The CDI was completed by the children's mothers. tThe marked items in the receptive and expressive sections were counted, and the number of children's receptive and expressive vocabulary was calculated. The Vineland Adaptive Behavior Scales were used to ensure the absence of cognitive delays in the children [14]. In this study, we used the first two sections (from 1 to 2 years of age) of the scale. The Timz's Socioeconomic Status Questionnaire (2007) was used to assess socioeconomic status [15].

The Vineland test was used to examination both the groups in terms of age, sex, socioeconomic status, parent's education, and cognitive status. An independent T-test was used to investigate the homogeneity of the two groups in terms of age, socioeconomic status, and cognitive status. A chi-squared test was used to compare the two groups in terms of age; and a Fisher's exact test was used to compare the two groups in terms of mother's education. Finally, the data obtained from the two groups were analyzed by SPSS 20. The comparison between the two groups was made us- ing an independent T-test. In addition, in all the statistical tests, the level of significance was set at $\mathrm{P}=0.05$.

\section{Results}

As you can see in Tables 1 and 2, the findings indicated that the number of receptive and expressive words in children with CLP was less than in the normal children. There was a significant difference between the means of expressive words in the two groups, but the difference between the means of receptive words in the two groups was not significant.

\section{Discussion}

As shown in Tables 1, and according to the analyzed data, the children with CLP faced delay in the number of receptive words compared to their matched normal peers, but this difference was not statistically significant. The number of expressive words in the children with CLP was much lower than that in the normal children, and this difference was statistically significant. This finding was consistent with the results of a longitudinal study by Chapman and Hardin-Jones (2014), which showed that the size of expressive lexicon in children with CLP was lower than that in normal children for all ages [7].

Their study used CDI, which wasy similar to the present study. Consistent with the current study results, Lu and Fletcher (2010) also found that all the children with unrepaired cleft lip and palate had lower performances in vocabulary comprehension and expression compared to the normal group; this study is similar to the present study in terms of using the CDI. Fletcher believes that the difference may be due to the phonetic characteristics

Table 1. Comparison of the size of receptive vocabulary in the children with cleft lip and palate and the normal children.

\begin{tabular}{cccccccc}
\hline Group & Number & Maximum & Minimum & Mean & $\begin{array}{c}\text { Std. Devia- } \\
\text { tion }\end{array}$ & $\begin{array}{c}\text { Mean Dif- } \\
\text { ference }\end{array}$ & P-Value \\
\hline $\begin{array}{c}\text { Cleft lip and } \\
\text { palate }\end{array}$ & 30 & 261.00 & 17.00 & 120.7667 & 64.86627 & & \\
$\quad$ Normal & 30 & 359.00 & 29.00 & 151.0000 & 84.69214 & & 0.126 \\
\hline
\end{tabular}

Ilranian Rehabilitation Journal

Table 2. Comparison of the size of expressive vocabulary in the children with cleft lip and palate and the normal children.

\begin{tabular}{cccccccc}
\hline Group & Number & Maximum & Minimum & Mean & $\begin{array}{c}\text { Std. Devia- } \\
\text { tion }\end{array}$ & $\begin{array}{c}\text { Mean Dif- } \\
\text { ference }\end{array}$ & P-Value \\
\hline $\begin{array}{c}\text { Cleft lip and } \\
\text { palate }\end{array}$ & 30 & 70.00 & 0.00 & 12.1667 & 15.91591 & & \\
Normal & 30 & 240.00 & 2.00 & 32.7667 & 45.21266 & & 0.022 \\
\hline
\end{tabular}


of Putonghua language because there is a close relationship between speech and vocabulary, especially in the early stages of vocabulary development [8].

The study findings were also consistent with Scherer \& Williams (2008), but in addition to the CDI, they used another instrument: the SICD [4]. In another study by Priester and Goorhuis-Brouwer (2008), no significant differences were found between the two groups in terms of language comprehension and production. Their findings confirmed the study findings regarding the absence of any delay in receptive language, and refute the study findings in terms of a delay in expressive language [10].

The study findings were also consistent with the results of a longitudinal study by Broen (1998) on early cognitive and language development in children with CLP. The only difference between Broen (1998) and the present study is the use of different instruments. Broen used the mental scale of the Bayley Scales of Infant Development (BSID), the Minnesota Child Development Inventory (MCDI), the Mean Length of Utterance (MLU), and the Vocabulary Acquisition at 24 months of age.

He has stated that since the children with CLP are vulnerable to middle ear infections, an early decrease in hearing can cause vocabulary inabilities. He has also suggested that the interaction patterns between children and their mothers can play a part in vocabulary delays in children with CLP. Broen has also stated that the children with more intelligible speech appropriate to their ages receive better feedbacks. However, this does not mean that a child's pronunciations need to be correct in order for their speech to be understood, but the speech needs to be understandable by the parents or caregivers so that they can provide appropriate feedbacks on the child's speech. In other words, if parents recognize their child's production of a word, it is more likely for the word to enter the child's lexicon, and if they do not recognize the child's production, the production goes unrewarded and the word does not enter the child's lexicon.

Broen has also stated that another reason for vocabulary delays may be some deficiencies in the size of the consonant inventory and the number of consonants produced before and after palate surgery. In other words, the speed of vocabulary development is affected by the early word choices and word attempts. Therefore, children prefer to add those words to their lexicon whose sounds are present in their lexicon. This phenomenon of selecting or avoiding words in children with CLP is a cause for great concern [2].
Yong (2010) also showed that the Chinese Singaporean pre-school children with CLP showed much more problems than their matched normal peers in terms of expressive use of vocabulary and language structure; this finding confirms the present study findings [1]. Some other researchers have also emphasized that vocabulary delays in children with CLP may have genetic causes and may result from a dysfunction in auditory short-term memory $[16,17]$. Moreover, there are evidences that indicate poor speech can have an inhibiting effect on the conversational interactions between a child and their caregivers. In other words, a poor speech reduces accurate caregiving patterns. In fact, learning primary vocabulary through interaction can be related to the development of early speech in children with CLP, as well as in normal children [18].

\section{Conclusion}

Given that a delay in diagnosis and evaluation of children with CLP can have irreparable impacts on them, the present study showed that children with CLP are in risk of experiencing delays in the development of expressive language. This compels us to pay attention to language problems of these children, as well as their speech problems, and provide early and timely interventions for them. The study findings indicate that language evaluation should be a routine procedure in team sessions [19]. Availability of parent questionnaires like the CDI can help therapy teams to examine language development in all children with CLP.

\section{Acknowledgements}

This paper is based on a master's thesis. We would like to thank the Department of Speech Therapy at the University of Social Welfare and Rehabilitation Sciences and our colleague, Mina Fotuhi, for their support in this research. We would also like to sincerely thank the personnel of Isfahan's health centers and the participant's families for their cooperation.

\section{Conflict of Interest}

The authors declared no conflict of interests.

\section{References}

[1] Young SE, Purcell AA, Ballard KJ. Expressive language skills in Chinese Singaporean preschoolers with nonsyndromic cleft lip and/or palate. International Journal of Pediatric Otorhinolaryngology. 2010; 74(5):456-64. doi: 10.1016/j. ijporl.2010.01.014 
[2] Broen PA, Devers MC, Doyle SS, Prouty JM, Moller KT. Acquisition of linguistic and cognitive skills by children with cleft palate. Journal of Speech, Language, \& Hearing Research. 1998; 41(3):676-87. doi: 10.1044/jslhr.4103.676

[3] Scherer NJ, D'Antonio L. Language and play development in toddlers with cleft lip and/or palate. American Journal of Speech-Language Pathology. 1997; 6(4):48-54. doi: 10.1044/1058-0360.0604.48

[4] D'Antonio L, Scherer NJ. Communication disorders associated with cleft palate: Comprehensive cleft care. New York: McGraw Hill Professional; 2008.

[5] Kummer A. Cleft palate \& craniofacial anomalies: Effects on speech and resonance. $3^{\text {rd }} \mathrm{ed}$. New York: Cengage Learning; 2007.

[6] Kushner KG. Therapy techniques for cleft palate speech and related disorders. $1^{\text {st }}$ ed. New York: Singular Publishing Group Inc; 2001.

[7] Hardin-Jones M, Chapman KL. Early lexical characteristics of toddlers with cleft lip and palate. Cleft Palate-CranioFacial Journal. 2014; 51(6):622-631. doi: 10.1597/13-076

[8] Lu Z, Ma L, Luo Y, Fletcher P. The effects of unrepaired cleft palate on early language development in Chinese infants. The Cleft Palate-Craniofacial Journal. 2010; 47(4):400-4. doi: $10.1597 / 08-223.1$

[9] Scherer NJ, Williams AL, Proctor-Williams K. Early and later vocalization skills in children with and without cleft palate. International Journal of Pediatric Otorhinolaryngology. 2008; 72(6):827-40. doi: 10.1016/j.ijporl.2008.02.010

[10] Priester GH, Goorhuis-Brouwer SM. Speech and language development in toddlers with and without cleft palate. International Journal of Pediatric Otorhinolaryngology. 2008; 72(6):801-6. doi: 10.1016/j.ijporl.2008.02.004

[11] Morris H, Ozanne A. Phonetic, phonological, and language skills of children with a cleft palate. The Cleft Palate-Craniofacial Journal. 2003; 40(5):460-70.

[12] Broen PA, Devers MC, Doyle SS, Prouty JM, Moller KT. Acquisition of linguistic and cognitive skills by children with cleft palate. Journal of Speech Language and Hearing Research. 1998; 41(3):676. doi: 10.1044/jslhr.4103.676

[13] Kazemi Y, Nematzadeh S, Hajian T, Heidari M, Daneshpajouh T, Mirmoeini M. [The validity and reliability coefficient of Persian translated McArthur-Bates Communicative Development Inventory (Persian)]. Journal of Research in Rehabilitation Sciences. 2008; 4(1):45-51.

[14] Sorayya M. [A comparative study of size of expressive lexicon in prematurely born children with full-term 18-36 month's children (Persian)] [MA thesis]. Isfahan: Isfahan University of Medical Sciences; 2008.

[15] Habibikalibar R. [Examination of effective factors in sexual differences in progress of fourth graders in math (TIMSS 2007) (Perian)]. Quarterly Journal of Education. 2013; 2:65-82.

[16] Richman LC, Eliason M. Type of reading disability related to cleft type and neuropsychological patterns. Cleft Palate Journal. 1984; 21(1):1-6. PMID: 6584246

[17] Čeponien R, Hukki J, Cheour M, Haapanen ML, Ranta R, Näätänen R. Cortical auditory dysfunction in children with oral clefts: relation with cleft type. Clinical Neurophysiology. 1999; 110(11):1921-6. doi: 10.1016/s1388-2457(99)00152-2

[18] Frederickson MS, Chapman KL, Hardin-Jones M. Conversational skills of children with cleft lip and palate: a replication and extension. Cleft Palate-Craniofacial Journal. 2006; 43(2):179-88. doi: 10.1597/04-086.1

[19] Scherer NJ, D'Antonio LL. Parent questionnaire for screening early language development in children with cleft palate. The Cleft Palate-Craniofacial Journal. 1995; 32(1):7-13. doi 10.1597/1545-1569(1995)032<0007:pqfsel>2.3.co;2

[20] Shemshadi H, Rezaei N. [Review: Speech rehabilitation in post cleft lip and palate reconstruction (Persian)]. Journal of Rehabilitation. 2004; 5(3):55-59. 
